\title{
Type 2 diabetes mellitus in Bangladesh: a prevalence based cost-of-illness study
}

\author{
Afsana Afroz ${ }^{1}$, Khurshid Alam², Liaquat Ali ${ }^{3}$, Afsana Karim", Mohammed J. Alramadan', Samira Humaira Habib ${ }^{4}$,
} Dianna J. Magliano ${ }^{1,5}$ and Baki Billah ${ }^{1^{*}}$ (D)

\begin{abstract}
Background: The economic burden of type 2 diabetes has not been adequately investigated in many low- and lower middle-income countries, including Bangladesh. The aim of this study was to estimate the cost-of-illness of type 2 diabetes and to find its determinants in Bangladesh.
\end{abstract}

Methods: A cross-sectional study was conducted in 2017 to recruit 1253 participants with type 2 diabetes from six diabetes hospitals, providing primary to tertiary health care services, located in the northern and central regions of Bangladesh. A structured questionnaire was used for face-to-face interviewing to collect non-clinical data. Patients' medical records were reviewed for clinical data and hospital records were reviewed for hospitalisation data. Cost was calculated from the patient's perspective using a bottom-up methodology. The direct costs for each patient and indirect costs for each patient and their attendants were calculated. The micro-costing approach was used to calculate direct cost and the human capital approach was used to calculate indirect cost. Median regression analysis was performed to identify the determinants of average annual cost.

Results: Among the participants, 54\% were male. The mean ( \pm SD) age was $55.1 \pm 12.5$ years and duration of diabetes was $10.7 \pm 7.7$ years. The average annual cost was US\$864.7 per patient. Medicine cost accounted for $60.7 \%$ of the direct cost followed by a hospitalisation cost of $27.7 \%$. The average annual cost for patients with hospitalisation was 4.2 times higher compared to those without hospitalisation. Being females, use of insulin, longer duration of diabetes, and presence of diabetes complications were significantly related to the average annual cost per patient.

Conclusions: The cost of diabetes care is considerably high in Bangladesh, and it is primarily driven by the medicine and hospitalisation costs. Optimisation of diabetes management by positive lifestyle changes is urgently required for prevention of comorbidities and complications, which in turn will reduce the cost.

Keywords: Burden of diabetes, Cost-of-illness, Direct cost, Indirect cost, Management plan, Type 2 diabetes

\section{Background}

Diabetes is one of the most prevalent non-communicable diseases globally and, currently, the disease is a major public health issue in developing countries because of its chronic nature, rapidly increasing prevalence, related complications, and the requirement of long-term care. The higher prevalence of diabetes is related to an increased prevalence of obesity, population ageing, population growth, urbanisation and physical inactivity [1]. The

\footnotetext{
* Correspondence: baki.billah@monash.edu

${ }^{1}$ Department of Epidemiology and Preventive Medicine, School of Public Health and Preventive Medicine, Monash University, 553 St. Kilda Rd., Level 4 , Melbourne, VIC 3004, Australia

Full list of author information is available at the end of the article
}

International Diabetes Federation (IDF) estimated that, worldwide, approximately 425 million people had diabetes in 2017; the number is projected to be 629 million by 2045. For treating and preventing diabetes and its related complications, an estimated US\$727 billion was spent in 2017, which represented an $8 \%$ increase from that estimated for 2015. The cost has been projected to be US\$776 billion by 2045 [2]. The annual cost for people with diabetes is mainly related to direct (e.g. cost for medicine, hospital care, laboratory tests, etc.) and indirect costs (e.g. productivity loss from disability, premature mortality, etc.) [3].

(C) The Author(s). 2019 Open Access This article is distributed under the terms of the Creative Commons Attribution 4.0 International License (http://creativecommons.org/licenses/by/4.0/), which permits unrestricted use, distribution, and reproduction in any medium, provided you give appropriate credit to the original author(s) and the source, provide a link to the Creative Commons license, and indicate if changes were made. The Creative Commons Public Domain Dedication waiver (http://creativecommons.org/publicdomain/zero/1.0/) applies to the data made available in this article, unless otherwise stated. 
Compared to people living in high-income countries, people in low- and lower middle-income countries (LMICs) have a lack of access to health insurance or publicly available medical services. Thus, they pay a larger share of out-of-pocket (OOP) health expenditures. Furthermore, in some LMICs, people with diabetes and their families bear almost all of the expenditure related to diabetes care [4]. The prevalence of diabetes has escalated more rapidly in South East Asia than in any other large region in the world [2]. Literature showed that about 90 to $95 \%$ of all diagnosed diabetes cases of this region are type 2 diabetes $[5,6]$. In Bangladesh, the estimated prevalence of diabetes among adults was $9.7 \%$ in 2011 [7] and the number is projected to be 13.7 million by 2045 [2]. According to the Bangladesh National Health Accounts, in 2010, Bangladesh spent US\$2.3 billion on health (or US\$16.20 per person per year) and $64 \%$ of this cost came from OOP payments [8]. However, according to the World Health Organization (WHO), in 2014, Bangladesh spent US\$88 per person per year on health [9]. It has been observed that, on average, a household spent $7.5 \%$ of its total income on receiving health care, with the poorest $20 \%$ of the households spending approximately $13.5 \%$ of their income on it [8]. The per capita gross domestic product (GDP) of Bangladesh was US\$1677 in 2018 [10], and nearly onethird $(31.5 \%)$ of the population in the country was below the poverty line [11]. Hence, the OOP health care expenditure posed a notable economic burden on the Bangladeshi population.

In high-income nations, such as the USA [12-15] and in some European [16] and upper middle-income countries $[17,18]$, the economic burden of diabetes is wellacknowledged and investigated. Most of these studies have estimated the economic burden in terms of cost, while others $[14,15,17]$ investigated the factors (e.g. patients' demographics, complications, payment methods and health care utilisation) correlated with the total cost. Low- and lower middle-income countries represent $80 \%$ of the global diabetic population [2]; however, researchbased evidence on diabetes management-related cost is limited for most of these countries, including Bangladesh. A study [19] in Bangladesh that addressed the cost and its determinants recruited a relatively small sample from a single hospital located in the capital city, and thus covered mostly urban residents. Furthermore, the cost was calculated from the outpatient department only, which may underestimate the average annual cost.

Thus, the aim of this study was to estimate the average annual cost and to find its determinants, where the cost data included both outpatients and hospitalisation. This study's findings will provide the most up-to-date information on the economic burden incurred by people with type 2 diabetes mellitus (T2DM) in Bangladesh, which will be useful as an important aid in the planning of health care needs and allocation of scarce resources.

\section{Methods \\ Study design and study population}

A cross-sectional study was conducted with a prevalence-based approach [20]. Data was collected from six hospitals (specialising in diabetes) where patients' records were available for the previous years, located in the northern and central regions of the country. Two of these hospitals are from the central region, providing primary to tertiary health care, particularly to urban residents. The remaining hospitals are from the northern region, two of them providing primary and secondary health care and the other two providing primary to tertiary health care to people residing in semi-urban and rural locations. Patients attending hospitals providing primary and secondary but in need of tertiary care are usually referred to the tertiary care hospitals. Due to a similar social and economic status for people living in the northern and southern regions, the patients from the hospitals of the northern region are comparable to those living in the southern region of the country. Thus, no hospitals were selected from the southern region. The Diabetic Association of Bangladesh (BADAS), a not-forprofit but mostly self-sustaining social welfare organisation, directly or indirectly (through affiliated local associations) owns all the selected hospitals. BADAS, the highest diabetes care provider, has 75 diabetic centres/ hospitals which cover all 64 districts (second highest level tire of regional administration) across the country. Due to lack of adequate services related to diabetes in public hospitals, particularly in peripheral areas, majority of the people with diabetes are treated and managed by the hospitals under BADAS. The hospitals were purposively selected to ensure that the study included patients from rural-urban as well as professionally mixed populations (e.g. service holders, businessmen, farmers, day labours, housewives, etc.) attending various levels of health care services. Between April and September 2017, 1253 participants were recruited using systematic random sampling and probability proportional to size (PPS) methods (Fig. 1). The target population comprised registered adults of either gender with a minimum one-year duration of T2DM. People with other types of diabetes or who were pregnant at the time of data collection were excluded as those people may have some additional expenses other than T2DM. A team of trained data collectors was involved in the data collection. At the beginning of the interview, the data collectors provided an explanatory statement to each participant and, upon his/her agreement to participate by signing the consent form, participants were interviewed face-to-face. Participants were recruited from the outpatient department of 


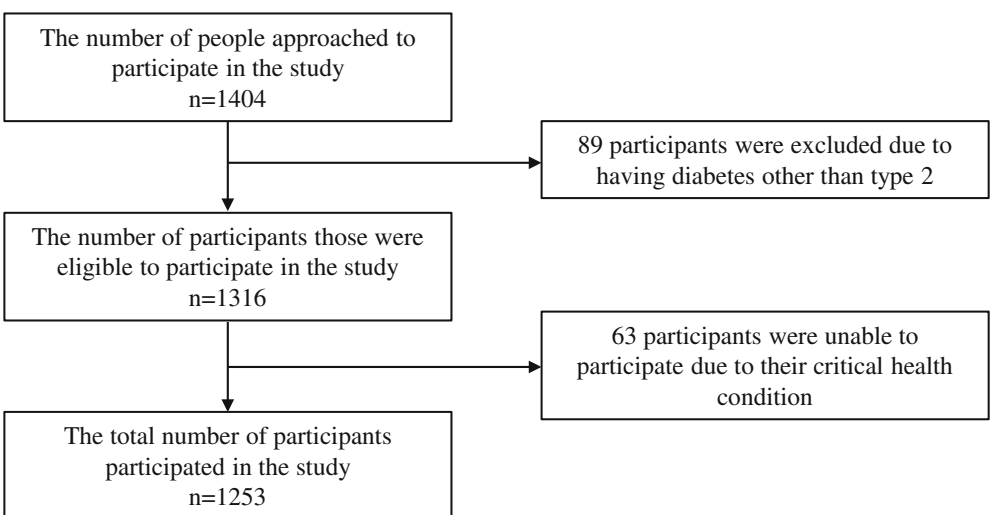

Fig. 1 Study participant's recruitment flowchart

the selected hospitals and those who were referred to hospital admission were followed-up to collect their hospitalisation information from the hospital inpatient department.

\section{Data collection instrument}

A structured questionnaire (Additional file 1) was developed and used in a secured web-based application, Research Electronic Data Capture (REDCap), for data collection [21]. Prior to the main survey, the content validity of the questionnaire was evaluated and pretested, using a pilot study conducted in a tertiary care hospital. The questionnaire gathered each patient's details and demographics, diabetes-related information, cost-related information and the patient's lifestyle behaviour. Patients' medical records (guide books) were also reviewed to retrieve information pertaining to clinical status and the number of medical services received during the previous year. To obtain information about the types and quantities of currently prescribed medicine, a copy of the prescription was kept in the REDcap application as an image for further use.

\section{Calculation of costs}

The total cost of T2DM was calculated from the patient's perspective for the year 2017, considering direct and indirect costs as the major components. Direct cost was estimated using a bottom-up approach for primary data collection [22] and divided into the two following sub-categories: direct medical costs, which comprise the costs of hospitalisation, outpatient visits, medicine, laboratory tests, and other service utilisation (including the use of self-monitoring blood glucose and consumables); and direct non-medical costs, which comprise the cost of transportation and meals en- route to the hospital.

The micro-costing approach was used to identify cost items in as much detail as possible for calculating direct cost [23]. Cost per daily dose [24] of each medicine and therapy was defined. Costs related to medicine, consultancy and laboratory tests that patients paid OPP were collected from a tertiary level hospital located in the central region. It should be noted that the health insurances support is literally non-exists in Bangladesh, thus all payments met by OPP. All hospitals under the BADAS are homogeneous; thus, there is a negligible cost variation between the selected hospitals. For other components of direct medical cost and direct non-medical cost, each participant's responses to the questionnaire were considered as a reference. Each component of direct cost was calculated by multiplying the unit cost with the quantities of medical services received during the previous year. The cost of hospitalisation (including hospital stay, medicine and laboratory tests during the stay) was retrieved for each patient from their hospital record, which was provided by the accounts department of the hospital. The total direct cost was calculated by adding up all components of direct medical and direct nonmedical costs.

The indirect cost was calculated for both patients and their attendants' en-route to the hospital. The productive time lost to attend outpatient visits and during hospital admission was recorded based on the information provided by the patients and their attendants. The human capital approach [25] was used to calculate the indirect cost for those who were productive and in the formal workforce or housewives, but not for people who were unable to work (retired or ill health) or who chose not to work. The productivity loss of housewives was calculated using the minimum wage rate of Bangladesh (US\$224/annum) [26] as well as the median income of the participants who were in the formal workforce. The total cost was calculated by adding up total direct and total indirect costs.

All costs were calculated in Bangladeshi currency, Taka (BDT) and then, to add an international perspective, they 
Table 1 General characteristics of the study participants

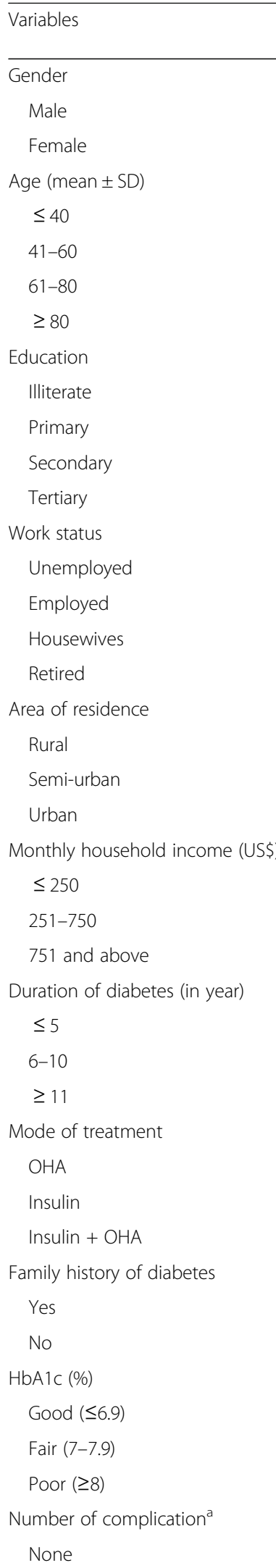

Table 1 General characteristics of the study participants (Continued)

\begin{tabular}{lc}
\hline Variables & $\begin{array}{l}n(\%) \\
(n=1253)\end{array}$ \\
\hline One or two & $613(48.9)$ \\
Three or more & $182(14.5)$ \\
History of co-morbidity & \\
None & $296(23.6)$ \\
Hypertension & $524(41.8)$ \\
Dyslipidaemia & $151(12.0)$ \\
Hypertension + dyslipidaemia & $283(22.6)$ \\
\hline $\begin{array}{l}\text { OHA Oral hypoglycaemic agent } \\
{ }^{a} \text { Complications include coronary artery disease, stroke, diabetic foot, } \\
\text { nephropathy, retinopathy and neuropathy }\end{array}$
\end{tabular}

161 (12.8)

239 (19.1)

566 (45.2)

$287(22.9)$

36 (32.8)

411 (40.5)

508 (23.8)

$298(2.9)$

174 (13.9)

$162(12.9)$

917 (73.2)

447 (35.7)

497 (39.7)

309 (24.6)

$360(28.8)$

348 (27.7)

$545(43.5)$

$432(34.5)$

$87(6.9)$

734 (58.6)

734 (58.7)

433 (34.6)

$820(65.4)$

$182(18.2)$

198 (19.8)

$621(62.0)$

458 (36.6) were converted into US\$ using the mid-year currency conversion rate for the year 2017 (US\$1 = BDT80).

\section{Ethical approval}

The study has been approved by the Monash University Human Research Ethics Committee (ID: 1469), the Ethical Review Committee of the Bangladesh University of Health Sciences (BUHS) and the Ethical Review Committee of the BADAS.

\section{Statistical analysis}

Descriptive statistics includes mean with standard deviation for numerical data and frequency with percentage for categorical data. A normality test of cost data was performed using histogram, Q-Q plot and the ShapiroWilk test. Cost data was right skewed; hence, mean and median with percentiles was used for reporting it. A median regression was run to determine the factors related to average annual cost. A bootstrapping method was used to calculate the $95 \%$ confidence interval $(\mathrm{CI})$ of regression coefficients [27]. A one-way sensitivity analysis was performed to evaluate the assumption that the use of minimum wage to calculate the indirect cost of housewives may give the lowest estimate. A two-way sensitivity analyses were undertaken to explore the change in average annual cost with assumptions of a $25 \%(+/-)$ change in the prevalence of insulin use and $25 \%(+/-)$ change in the prevalence of T2DM related complications. The statistical software package STATA SE version 15.0 was used for data analysis and a $p$-value of 0.05 or less was considered to be statistically significant.

\section{Results}

General characteristics of the study participants

The general characteristics of the study participants are presented in Table 1. Among the 1253 participants with T2DM, 681 (54.3\%) were male. The mean age of patients was $55.1 \pm 12.5$ years. Approximately $45 \%$ of participants 
had a secondary level education and $23 \%$ had a tertiary level education. About two-fifths (40.5\%) of the participants were employed and about a quarter (23.8\%) were housewives. Three-quarters (73.2\%) of the participants resided in urban areas and $51.2 \%$ of participants had a median monthly household income of US\$375 (BDT30, 000). Mean duration of diabetes was $10.9 \pm 7.7$ years and $43.5 \%$ of the participants had diabetes for more than 10 years. More than half of the participants (58.6\%) managed diabetes by a combination of an oral hypoglycaemic agent (OHA) and insulin, 34.5\% by OHA only (merging $1.8 \%$ of people with lifestyle modification with OHA only), and $6.9 \%$ by insulin only. More than half (55.9\%) of the participants moderately adhered to medication, followed by $37.2 \%$ with high adherence, with only $6.9 \%$ having poor adherence. About one-third (34.6\%) of the participants had family history of diabetes; only $19.8 \%$ had fair (HbA1c 7-7.9\%) and 62\% had poor (HbA1c $\geq$ $8 \%)$ glycaemic control. About half (48.9\%) of the participants had up to two diabetes-related complications (coronary artery disease, stroke, diabetic foot, nephropathy, retinopathy and neuropathy) and $14.5 \%$ had three or more complications. The study results showed that 41.8\% had hypertension, $12 \%$ had dyslipidaemia, and $22.6 \%$ had both. The mean productive time lost during outpatient visits was $7.3 \pm 1.5 \mathrm{~h}$ per month. For patients with a history of hospitalisation, productive time lost was $10.4 \pm 8.8$ days per year (data is not shown in the table).

\section{Cost-of-illness by socio demographic and clinical characteristics}

Cost-of-illness (total cost) by socio-demographic and clinical characteristics is presented in Table 2. The results showed that for each variable, direct cost is higher compared to indirect cost. The average annual cost increased with the increasing age, which ranged from US $\$ 588$ for aged $<=40$ years to US $\$ 1434$ for aged $>=80$ years $(p<0.001)$. Illiterate people spent the lowest (US\$637) and that was highest (US\$962) for people with up to secondary level education $(p=0.004)$. The average annual cost was higher for retired people (US\$1062, $p=0.001$ ) compared to unemployed people (US\$676). People residing in rural areas (US\$422) spent less compared to people living in urban areas (US\$1024, $p<0.001)$, and the high-income group spent more (US\$1062, $p<0.001$ ) than the low-income group. The average annual cost increased progressively with the increased duration of T2DM $(p<0.001)$ and people with diabetes duration of more than 10 years spent US $\$ 1160.8$ per year. The average annual cost for insulin users with a combination of OHA was US $\$ 1042.8$ compared to US\$526.2 for only OHA users $(p<0.001)$. As the number of complications increased, the average annual cost increased $(p<0.001)$. People with the presence of three or more complications spent US $\$ 1351.5$ annually compared to US\$532.2 for people without any complication. Likewise, people with the presence of both hypertension and dyslipidaemia had an average annual cost of US\$1022.6 compared to that of US\$659.4 for those with no comorbidity $(p<0.001)$.

\section{Annual cost-of-illness (COI) of diabetes care}

Table 3 presents the estimated average annual cost per person by components of direct and indirect costs. The average annual cost of diabetes care was US\$864.7, of which the direct cost was $90.5 \%$ with a mean of US\$781.7 and the indirect cost was $9.5 \%$ with a mean of US\$82.9. Without hospitalisation, the average annual cost was US $\$ 409.8$, which increased to US $\$ 1705.2$ with hospitalisation. Furthermore, Table 3 shows that of the overall direct cost, direct medical and non-medical costs were 96.9 and $3.1 \%$, respectively. The medicine cost accounted for the largest share $(60.7 \%)$ of overall direct cost followed by the hospitalisation cost (27.7\%). Medicine cost was also the highest source of direct cost (83.5\%) for patients without hospitalisation. For patients with hospitalisation, medicine cost contributed $50.7 \%$ of direct cost followed by a hospitalisation cost of $39.9 \%$. The average annual indirect cost was approximately four times higher for patients with hospitalisation (US\$158.9) compared to that of patients without hospitalisation (US\$41.8).

\section{Sensitivity analysis}

The result of the one-way sensitivity analysis showed that use of the median income of the study participants instead of the minimum wage increased the indirect cost by $23 \%$. However, the estimated average annual cost using the minimum wage rate of Bangladesh was US\$853 (95\% CI US\$795.1-US\$911.7), while it was US\$864.7 (95\% CI 806.5-922.9) using the median income of the study participants. The difference between these two estimates is insignificant as the CI overlapped each other.

The results of a two-way sensitivity analyses showed that the average annual cost increased by $2.9 \%$ (US\$ $\$ 865$ vs US\$890) when insulin use was increased by $25 \%$ and that decreased by $4 \%$ (US $\$ 865$ vs US\$830) when insulin use was decreased by $25 \%$. A $25 \%$ increase in prevalence of complications lead to a $5.3 \%$ (US\$865 vs UD\$898) increment of average annual cost, while it decreased by $3.9 \%$ (US $\$ 865$ vs US\$819) with a $25 \%$ reduction in complications.

\section{Determinants of cost-of-illness}

The results of simple and multiple median regression analyses are presented in Table 4 . In the simple median regression analysis, age group $61-80$ years (US $\$ 221.91, p<0.001$ ) 
Table 2 Details of annual cost in US\$ by socio-demographic and clinical characteristics of the study participants

\begin{tabular}{|c|c|c|c|c|c|c|}
\hline \multirow[t]{2}{*}{ Variables } & \multicolumn{2}{|c|}{ Direct cost } & \multicolumn{2}{|c|}{ Indirect cost } & \multicolumn{2}{|c|}{ Total cost } \\
\hline & Mean & Median (percentiles) & Mean & Median (percentiles) & Mean & Median (percentiles) \\
\hline \multicolumn{7}{|l|}{ Gender $^{\mathrm{b}}$} \\
\hline Male & 795.2 & $456.1(273.6,893.4)$ & 81.6 & $19.5(0,62.5)$ & 876.9 & $497.9(292.0,977.3)$ \\
\hline Female & 765.7 & $446.6(278.8,905.2)$ & 84.4 & $52.1(16.1,93.7)$ & 850.1 & $516.89(332.7,988.3)$ \\
\hline \multicolumn{7}{|l|}{ Age $\left(\right.$ years) ${ }^{c}$} \\
\hline$\leq 40$ & 519.6 & $331.1(205.4,564.9)$ & 68.8 & $41.6(18.48,72.91)$ & 588.4 & $385.7(241.0,616.2)$ \\
\hline $41-60$ & 738.7 & $421.1(270.3,784.7)$ & 103.0 & $52.1(19.5,104.2)$ & 841.8 & $476.2(310.1,860.1)$ \\
\hline $61-80$ & 934.9 & $587.4(337.1,1168.9)$ & 56.1 & $0(0,52.1)$ & 991.0 & $613.7(351.3,1247.3)$ \\
\hline$>80$ & 1376.9 & $1052.1(682.9,1845.5)$ & 57.1 & $0(0,0)$ & 1434.1 & $1133.1(712.2,1936.1)$ \\
\hline \multicolumn{7}{|l|}{ Education ${ }^{c}$} \\
\hline Illiterate & 575.3 & $421.1(254.1,705.5)$ & 61.6 & $39.1(3.6,72.9)$ & 636.9 & $437.2(287.5,775.3)$ \\
\hline Primary & 759.5 & $513.1(291.3,958.0)$ & 59.3 & $31.2(0,72.9)$ & 818.9 & $536.41(323.5,1036.1)$ \\
\hline Secondary & 874.1 & $483.1(294.7,989.4)$ & 88.0 & $35.1(0,83.3)$ & 962.1 & $529.2(333.7,1092.1)$ \\
\hline Tertiary & 733.9 & $409.4(224.6,831.8)$ & 104.5 & $41.6(0,91.1)$ & 838.4 & $452.0(261.2,913.5)$ \\
\hline \multicolumn{7}{|l|}{ Work status $^{c}$} \\
\hline Unemployed & 627.5 & $469.0(298.7,598.3)$ & 48.0 & $0(0,0)$ & 675.6 & $469.0(298.7,606.2)$ \\
\hline Employed & 598.9 & $343.1(217.8,607)$ & 116.0 & $41.6(18.7,87.5)$ & 715.0 & $393.3(255.3,700.7)$ \\
\hline Housewives & 798.9 & $488.3(294.3,936.7)$ & 87.0 & $52.1(20.8,104.1)$ & 885.9 & $533.6(359.3,1025.1)$ \\
\hline Retired & 1027.0 & $617.4(369,1189.9)$ & 34.8 & $0(0,10.9)$ & 1061.9 & $644.3(374.2,1298.3)$ \\
\hline \multicolumn{7}{|l|}{ Area of residence ${ }^{c}$} \\
\hline Rural & 359.8 & $291.3(202.4,442.2)$ & 61.7 & $47.9(11.4,83.3)$ & 421.6 & $369.0(239.6,522.3)$ \\
\hline Semi-urban & 388.3 & $295.5(228.1,494.6)$ & 48.1 & $33.2(7.8,70.3)$ & 436.5 & $353.3(253.7,541.1)$ \\
\hline Urban & 931.3 & $545.3(324.9,1089.6)$ & 93.1 & $34.3(0,87.5)$ & 1024.4 & $590.3(361.4,1205.4)$ \\
\hline \multicolumn{7}{|c|}{ Monthly household income (US\$) } \\
\hline$\leq 250$ & 739.6 & $465.5(258.1,846.1)$ & 65.2 & $31.2(0,78.1)$ & 804.9 & $499.4(289.5,920.3)$ \\
\hline $251-750$ & 692.1 & $407.9(267.6,757.3)$ & 64.6 & $41.66(1.30,72.9)$ & 756.8 & $456.5(305.2,810.7)$ \\
\hline 751 and above & 986.8 & $571.8(340.5,1262.8)$ & 138.0 & $41.6(0,125.0)$ & 1124.9 & $499.4(289.5,920.3)$ \\
\hline \multicolumn{7}{|c|}{ Duration of diabetes (in year) ${ }^{c}$} \\
\hline$\leq 5$ & 526.3 & $325.8(220.8,539.2)$ & 53.7 & $32.6(10.4,67.1)$ & 580.1 & $378.9(260.2,589.0)$ \\
\hline $6-10$ & 645.9 & $398.0(258.3,691.7)$ & 61.4 & $41.6(3.9,72.9)$ & 707.4 & $458.1(292.5,760.6)$ \\
\hline$\geq 11$ & 1044.1 & $679.8(378.8,1251.3)$ & 116.7 & $37.5(0,114.5)$ & 1160.8 & $746.6(418.3,1442.5)$ \\
\hline \multicolumn{7}{|c|}{ Mode of treatment ${ }^{c}$} \\
\hline $\mathrm{OHA}$ & 476.2 & $291.4(209.6,511.2)$ & 49.9 & $31.2(4.0,62.5)$ & 526.17 & $335.0(238.7,534.3)$ \\
\hline Insulin & 702.6 & $441.9(224.3,842.3)$ & 67.2 & $41.6(8.8,83.3)$ & 769.89 & $477.1(259.8,902.8)$ \\
\hline Insulin + OHA & 970.9 & $586.0(368.9,1129.6)$ & 104.2 & $41.6(0,104.1)$ & 1075.20 & $642.7(412.4,1223.7)$ \\
\hline \multicolumn{7}{|c|}{ Family history of diabetes ${ }^{b}$} \\
\hline Yes & 818.4 & $487.3(287.0,964.3)$ & 97.1 & $41.6(9.8,93.7)$ & 915.6 & $524.3(321.7,1100.8)$ \\
\hline No & 762.4 & $441.4(270.5,879.9)$ & 75.4 & $31.2(0,72.9)$ & 837.9 & $493.1(298.9,954.2)$ \\
\hline \multicolumn{7}{|l|}{ HbA1c (\%) } \\
\hline Good $(\leq 6.9)$ & 527.1 & $318.9(205.9,513.3)$ & 84.5 & $31.2(0,65.1)$ & 611.7 & $367.5(234.2,562.8)$ \\
\hline Fair (7-7.9) & 552.1 & $366.6(242.3,637.5)$ & 53.2 & $26.0(0,62.5)$ & 605.4 & $409.9(277.8,665.1)$ \\
\hline Poor $(\geq 8)$ & 567.9 & $398.9(267.2,633.2)$ & 58.5 & $36.4(7.8,72.9)$ & 626.5 & $450.4(300.7,717.3)$ \\
\hline \multicolumn{7}{|c|}{ Number of complication ${ }^{a, c}$} \\
\hline None & 466.8 & $295.9(207.3,507.0)$ & 56.3 & $31.2(15.6,65.1)$ & 523.2 & $347.9(237.8,549.2)$ \\
\hline
\end{tabular}


Table 2 Details of annual cost in US\$ by socio-demographic and clinical characteristics of the study participants (Continued)

\begin{tabular}{|c|c|c|c|c|c|c|}
\hline \multirow[t]{2}{*}{ Variables } & \multicolumn{2}{|c|}{ Direct cost } & \multicolumn{2}{|c|}{ Indirect cost } & \multicolumn{2}{|c|}{ Total cost } \\
\hline & Mean & Median (percentiles) & Mean & Median (percentiles) & Mean & Median (percentiles) \\
\hline One or two & 657.5 & $379.9(261.8,670.7)$ & 81.9 & $36.4(0,83.3)$ & 739.4 & $437.1(293.5,739.7)$ \\
\hline Three or more & 1234.3 & $966.9(511.1,1519.8)$ & 117.1 & $43.7(0,130.2)$ & 1351.5 & $1036.8(547.8,1718.5)$ \\
\hline \multicolumn{7}{|l|}{ History of co-morbidity ${ }^{c}$} \\
\hline None & 595.5 & $354.2(219.8,580.7)$ & 63.8 & $31.2(10.4,72.9)$ & 659.3 & $418.2(260.7,632.8)$ \\
\hline Hypertension & 870.1 & $533.9(317.5,1041.9)$ & 94.3 & $41.6(0,91.1)$ & 964.4 & $582.4(362.7,1150.3)$ \\
\hline Dyslipidaemia & 566.8 & $332.6(228.1,561.9)$ & 56.9 & $27.3(9.1,62.5)$ & 623.7 & $376.1(259.6,608.8)$ \\
\hline Hypertension + dyslipidaemia & 926.9 & $534.0(313.7,1041.3)$ & 95.7 & $41.6(0,91.1)$ & 1022.6 & $587.6(365,1143.5)$ \\
\hline
\end{tabular}

OHA Oral hypoglycaemic agent, HTN Hypertension

${ }^{\mathrm{a} C}$ Complications include coronary artery disease, stroke, diabetic foot, nephropathy, retinopathy and neuropathy. ${ }^{\mathrm{b}}$ Mann Whitney $\mathrm{U}$ test and ${ }^{\mathrm{c}} \mathrm{Kruskal}$ Wallis test were done for group comparison; $p$-value was considered significant at $p<0.05$

and more than 80 years (US\$741.58, $p<0.001$ ), treated with insulin alone (US\$140.69, $p=0.042$ ) as well as with a combination of OHA (US\$307.38, $p<0.001$ ), duration of diabetes more than 10 years (US\$368.68, $p<0.001$ ), poor (HbA1c $\geq 8 \%$ ) glycaemic control (US\$79.41, $p=0.009$ ), presence of any complication (US\$201.54 for one or two and US $\$ 287.72$ for more than two, $p<0.001$ ), presence of hypertension (US $\$ 254.89 p<0.001$ ) alone and hypertension with a combination of dyslipidaemia (US\$169.07, $p=0.001$ ) were significantly associated with higher costs.

Multiple regression analysis showed that the average annual cost was higher for females (US\$44.85, $p=0.036$ ). People treated with insulin with a combination of OHA (US\$152.87, $p<0.001$ ) also had higher costs compared to those treated with OHA only. Patients with a duration of diabetes of more than 10 years (US\$66.93, $p=0.025$ ) incurred a higher cost. Likewise, patients with the presence of any complication (US\$63.69 for one or two and US $\$ 440.93$ for more than two, $p<0.001$ ) had higher costs compared to those without any complication.

\section{Discussion}

Diabetes has become a major global economic burden in recent decades, but proper management of the factors related to it can be useful for reducing this burden. Diabetes is also an increasingly economic threat in Bangladesh, yet studies on an adequate estimation of COI for T2DM and its key drivers are limited; hence, the aim of this paper. This study involved a large representative sample that adequately investigated the economic burden of type 2 diabetes in Bangladesh from the patients' perspective. The key finding of this study was that the average annual cost for T2DM patient is US\$865 with the medicine cost being the highest contributor followed by the hospitalisation cost. The average annual cost for patients with hospitalisation was 4.2 times higher compared to those without hospitalisation.
The average annual cost for each person with T2DM in Bangladesh appears to be considerably higher than that reported in previous studies conducted in Bangladesh (US\$314) [19] and other South Asian countries such as India (US\$525) [28] and Pakistan (US\$197) [29]. One possible explanation of this difference may be because the studies conducted in Bangladesh and Pakistan addressed only outpatient department cost, which underestimated the overall cost. In contrast, some high- or upper middle-income Asian countries, for example, China (US\$1501.7) [30] and Singapore (US\$1575.6) [18], reported higher cost for diabetes management.

This study finding showed that cost increased with age, which is supported by previous studies [14, 17, 31]. Additionally, female gender was a factor more likely to incur higher cost. A study conducted in Bangladesh by Shamima et al. showed that females had better awareness about diabetes and were more regular in receiving follow-up check-ups [7], which may be related to higher cost. A study conducted in Hawaii by Bhattacharyya et al. [14] showed a similar result, while Krop et al. [31] in Maryland and Chaikledkaew et al. [32] in Thailand showed that the cost of care was higher for males.

An important finding of this study was that 13.5\% of participants had income less than the estimated average annual cost. Overall, a person with T2DM spent 9\% of his/her annual household income on management, which is a notable financial burden for a family. In South Asia, health insurance is practically non-existent, and almost all expenses are met through OOP, which creates a significant burden and sometimes leads to family impoverishment. This study showed that urban residents spent more than the rural residents (mean cost for urban: US\$1024.4, vs rural: US\$421.6). This may be because of people residing in urban areas have better education and a higher income, and thus can better afford to receive adequate treatment and access to specialised doctors. 
Table 3 Costs-of-illness of type 2 diabetes per person per year (in US\$) by components of direct and indirect costs

\begin{tabular}{|c|c|c|c|c|c|c|c|}
\hline Cost components & Mean & Median & $25^{\text {th }} p$, 75th $p$ & 90th $p$ & $\begin{array}{l}\% \\
\text { of total }\end{array}$ & $\begin{array}{l}\text { Total } \\
\text { COI }\end{array}$ & $\%$ of total CO \\
\hline \multicolumn{8}{|l|}{ Overall COI $(n=1263)$} \\
\hline \multicolumn{8}{|l|}{ a. Direct cost } \\
\hline i. Direct medical cost & & & & & 96.9 & & \\
\hline Outpatient visit & 11.8 & 6.3 & $2.2,12.5$ & 31.2 & 1.5 & $14,807.1$ & 1.4 \\
\hline Hospitalisation $^{a}$ & 216.7 & 496.6 & $0,276.7$ & 673.1 & 27.7 & $271,490.4$ & 12.7 \\
\hline Medicine & 474.5 & 331.0 & $205.3,474.5$ & 798.4 & 60.7 & $594,543.8$ & 54.9 \\
\hline Laboratory tests & 37.7 & 34.0 & $23.3,47.2$ & 62.1 & 4.8 & $47,311.9$ & 16.8 \\
\hline Other service utilisation ${ }^{\#}$ & 16.5 & 9.0 & 0,18 & 54.0 & 2.1 & 20,718 & 1.8 \\
\hline ii. Direct non-medical cost & & & & & 3.1 & & \\
\hline Transportation & 23.7 & 7.5 & $2.5,27.5$ & 62.5 & 3.0 & $29,748.7$ & 2.8 \\
\hline Meal & 0.7 & 0.0 & 0,0 & 2.5 & 0.1 & 931.4 & 0.1 \\
\hline Total direct cost & 781.7 & 453.6 & $276.6,893.4$ & 1705.0 & 100 & $979,551.3$ & 90.5 \\
\hline \multicolumn{8}{|l|}{ b. Indirect cost } \\
\hline Productivity loss of patient & 67.8 & 26.0 & $0,62.5$ & 145.8 & 81.8 & $85,062.5$ & 7.9 \\
\hline $\begin{array}{l}\text { Productivity loss of accompanied } \\
\text { person }\end{array}$ & 15.1 & 0.0 & 0,0 & 39.1 & 18.2 & $18,872.2$ & 1.7 \\
\hline Total indirect cost & 82.9 & 36.5 & $0,82.8$ & 187.5 & 100 & $103,934.8$ & 9.5 \\
\hline Total cost & 864.7 & 504.2 & $308.8,982.7$ & 1874.3 & & $1,083,486.0$ & \\
\hline \multicolumn{8}{|l|}{ Without hospital admission $(n=813)$} \\
\hline \multicolumn{8}{|l|}{ Direct cost } \\
\hline i. Direct medical cost & & & & & 93.9 & & \\
\hline Outpatient visit & 5.9 & 5.0 & $1.25,8.75$ & 12.5 & 1.6 & 4801.6 & \\
\hline Hospitalisation $^{a}$ & - & - & - & - & - & - & \\
\hline Medicine & 307.2 & 255.5 & $173.4,387.8$ & 520.1 & 83.5 & $249,827.3$ & \\
\hline Laboratory tests & 34.2 & 31.2 & $21.5,41.8$ & 53.9 & 9.3 & $27,828.6$ & \\
\hline Other service utilisation ${ }^{b}$ & 10.5 & 9.0 & 0,9 & 18.0 & 2.8 & 8523.0 & \\
\hline ii. Direct non-medical cost & & & & & 2.8 & & \\
\hline Transportation & 9.4 & 3.7 & $2,8.75$ & 21.0 & 2.6 & 7662.6 & \\
\hline Meal & 0.7 & 0.0 & $0,0.6$ & 2.3 & 0.2 & 524.5 & \\
\hline Total direct cost & 367.9 & 320.1 & $227.9,452.8$ & 608.9 & 100 & $299,167.5$ & \\
\hline \multicolumn{8}{|l|}{ Indirect cost } \\
\hline Productivity loss of patient & 34.7 & 24.7 & $0,52.1$ & 71.9 & 83.0 & $28,244.5$ & \\
\hline $\begin{array}{l}\text { Productivity loss of accompanied } \\
\text { person }\end{array}$ & 7.1 & 0.0 & 0,0 & 20.8 & 17.0 & 5790.9 & \\
\hline Total indirect cost & 41.8 & 31.3 & $3.9,62.5$ & 93.7 & 100 & $34,035.4$ & \\
\hline Total cost & 409.8 & 366.6 & $261.9,505.7$ & 662.7 & & $333,202.9$ & \\
\hline \multicolumn{8}{|l|}{ With hospital admission $(n=440)$} \\
\hline \multicolumn{8}{|l|}{ Direct cost } \\
\hline i. Direct medical cost & & & & & 96.7 & & \\
\hline Outpatient visit & 22.7 & 12.5 & $5,37.5$ & 51.3 & 1.5 & $10,005.5$ & \\
\hline Hospitalisation $^{a}$ & 617.0 & 419.4 & $247.3,753.2$ & 1303.9 & 39.9 & $271,490.4$ & \\
\hline Medicine & 783.4 & 469.9 & $346.7,764.0$ & 1455.4 & 50.7 & $344,716.5$ & \\
\hline Laboratory tests & 44.3 & 41.8 & $29.7,56.9$ & 71.6 & 2.9 & $19,483.4$ & \\
\hline Other service utilisation ${ }^{b}$ & 10.0 & 9.0 & 9,36 & 54.0 & 1.8 & $12,195.0$ & \\
\hline
\end{tabular}


Table 3 Costs-of-illness of type 2 diabetes per person per year (in US\$) by components of direct and indirect costs (Continued)

\begin{tabular}{|c|c|c|c|c|c|c|c|}
\hline Cost components & Mean & Median & $25^{\text {th }} p, 75$ th $p$ & 90th $p$ & $\begin{array}{l}\% \\
\text { of total }\end{array}$ & $\begin{array}{l}\text { Total } \\
\text { col }\end{array}$ & $\%$ of total COI \\
\hline ii. Direct non-medical cost & & & & & 3.3 & & \\
\hline Transportation & 50.2 & 31.2 & $15,62.5$ & 112.5 & 3.2 & $22,086.1$ & \\
\hline Meal & 0.9 & 0.0 & 0,0 & 2.5 & 0.1 & 406.9 & \\
\hline Total direct cost & 1546.3 & 1121.1 & $806.3,1845.9$ & 2927.7 & 100.0 & $680,383.8$ & \\
\hline \multicolumn{8}{|l|}{ Indirect cost } \\
\hline Productivity loss of patient & 129.1 & 35.1 & $0,145.8$ & 281.2 & 81.3 & $56,818.1$ & \\
\hline $\begin{array}{l}\text { Productivity loss of accompanied } \\
\text { person }\end{array}$ & 29.7 & 0.0 & 0,0 & 104.1 & 18.7 & $13,081.2$ & \\
\hline Total indirect cost & 158.9 & 67.7 & $0,182.9$ & 345.1 & 100.0 & $69,899.4$ & \\
\hline Total cost & 1705.2 & 1247.4 & $876.9,1996.6$ & 3353.8 & & $750,283.2$ & \\
\hline
\end{tabular}

${ }^{a}$ Hospitalisation includes hospital stay, medicine and laboratory tests during stay. ${ }^{\mathrm{b}}$ Other service utilisation includes use of self-monitoring blood glucose and consumables

The present results showed that direct cost had the largest share (90.5\%) of overall cost. Among all the cost components of overall direct cost, medicine cost was the major contributor (60.7\%). The studies conducted by Khowaja et al. [29] in Pakistan and Shobhana et.al [28] in India reported similar features. However, compared to these studies, the present study showed a much higher proportion of medicine cost. This difference may be related to many factors. Firstly, 93\% of the participants in this current study had high or medium adherence to medication, which incurs a higher medicine cost. Secondly, among them, $65.6 \%$ used either insulin alone or insulin with a combination of OHA, which is higher than that reported in another study in Bangladesh [33].

Table 4 Median regression analysis of total cost

\begin{tabular}{|c|c|c|c|c|c|c|}
\hline \multirow[t]{2}{*}{ Variables } & \multicolumn{3}{|l|}{ Unadjusted } & \multicolumn{3}{|l|}{ Adjusted } \\
\hline & Coefficients & $p$-value & 95\% confidence interval (Cl) & Coefficients & $p$-value & 95\% confidence interval (Cl) \\
\hline \multicolumn{7}{|l|}{ Gender (ref: Male) } \\
\hline Female & 19.03 & 0.492 & $-35.32-73.37$ & 44.85 & 0.036 & $3.02-86.68$ \\
\hline \multicolumn{7}{|l|}{ Age ( $\leq 40$ years) } \\
\hline $41-60$ years & 82.85 & 0.107 & $-17.79-183.49$ & 21.13 & 0.419 & $-30.13-72.39$ \\
\hline $61-80$ years & 221.91 & $<0.001$ & $113.60-330.24$ & 2.86 & 0.930 & $-60.70-66.41$ \\
\hline$\geq 80$ years & 741.58 & $<0.001$ & 499.87-938.30 & 170.76 & 0.708 & $-723.11-1064.64$ \\
\hline \multicolumn{7}{|l|}{ Mode of treatment (ref: OHA) } \\
\hline Insulin & 140.69 & 0.042 & $5.28-276.09$ & 65.40 & 0.260 & $-48.28-179.07$ \\
\hline Insulin + OHA & 307.38 & $<0.001$ & $237.90-377.65$ & 152.87 & $<0.001$ & $107.45-198.30$ \\
\hline \multicolumn{7}{|l|}{ Duration of diabetes (ref: $\leq 5$ year) } \\
\hline $6-10$ & 78.36 & 0.080 & $-9.42-166.15$ & 17.59 & 0.403 & $-23.68-58.82$ \\
\hline$\geq 11$ & 368.68 & $<0.001$ & $289.32-448.04$ & 66.93 & 0.025 & $8.55-125.32$ \\
\hline \multicolumn{7}{|l|}{ HbA1c (ref: $\leq 6.9$ ) } \\
\hline Fair (7-7.9) & 45.42 & 0.216 & $-26.60-177.43$ & -1.20 & 0.949 & $-63.50-59.51$ \\
\hline Poor $(\geq 8)$ & 79.41 & 0.009 & $20.30-138.53$ & 22.50 & 0.406 & $-30.58-75.58$ \\
\hline \multicolumn{7}{|l|}{ History of co-morbidity (ref: None) } \\
\hline Hypertension & 164.89 & $<0.001$ & $76.10-252.79$ & 30.13 & 0.213 & $-17.25-77.51$ \\
\hline Dyslipidaemia & -42.17 & 0.494 & $-163.00-78.66$ & 2.88 & 0.924 & $-65.16-61.91$ \\
\hline Hypertension+dyslipidaemia & 169.07 & 0.001 & $68.60-269.55$ & 53.07 & 0.098 & $-9.75-115.89$ \\
\hline \multicolumn{7}{|c|}{ Number of complication (ref: None) } \\
\hline One or two & 210.54 & $<0.001$ & $134.48-28,660$ & 63.69 & 0.003 & $21.70-105.68$ \\
\hline Three or more & 847.72 & $<0.001$ & $739.82-955.63$ & 440.93 & $<0.001$ & $274.08-607.85$ \\
\hline
\end{tabular}


The guidelines for treatment and management of diabetes in Bangladesh follows lifestyle management as the first line care, metformin as second line care and then insulin, etc. depending on the health requirement (presence of comorbidity and complications) of the patients. Moreover, as all medical costs come from out of pocket payments, people usually visit doctor when diabetes makes obstacle to their daily living. This explained why a very low number of participants $(1.8 \%)$ in this study were under lifestyle management. Thirdly, since insulin is very expensive in Bangladesh, it leads to a higher medicine cost. The result of other studies conducted in some developing countries [14, 34-37] also showed the medicine cost as a major contributor to direct cost.

Medicine was the highest source of direct cost (83.5\%) for patients without hospitalisation. Furthermore, for patients with hospitalisation, medicine cost was $50.7 \%$ of the direct cost followed by a hospitalisation cost of $39.9 \%$. However, a number of previous studies showed that the largest proportion of cost is attributable to hospitalisation followed by medicine cost. In the USA, hospitalisation cost accounted for $50 \%$ [38], while that was $55 \%$ in the Cost of Diabetes in Europe-Type II study [39].

In the present study, the cost of diabetes care substantially increased with the presence of comorbidities as well as complications related to T2DM. The cost was positively correlated with the increased number of comorbidities and complications leading to hospitalisation. This finding is supported by other studies in the developed [30, 37, 40-42] as well as in developing countries $[43,44]$. In addition to complications and comorbidities, the duration of diabetes also accelerates cost; likewise, cost increased for patients who had poor glycaemic control compared to good control. Similar results were reported in previous COI studies [28, 29, 37, 45].

A Median regression analysis showed that female gender, use of insulin, longer duration of diabetes, and presence of complications are the factors related to a higher annual average cost per person. A majority of these variables also appeared as contributing factors in previous studies [14, 15, 17, 28, 42]. Thus, optimisation of the management of diabetes-related complications is an imperative need for people with T2DM in Bangladesh, which has also reflected in the results of sensitivity analyses of the current study.

The present study showed that in 2017 the annual average cost per T2DM was US\$864.7, which is $52 \%$ of per capita GDP of Bangladesh [10] and 9.8 times higher than the general health care cost [9]. The burden of diabetes is influenced by many socio-economic and health care system factors, which consequently affects the cost of care. Early screening is one of the factors that may help to diagnose T2DM patients at an initial stage, thus avoiding complications. However, in developing countries, people often seek medical help when they have already developed some complications. In addition, inadequate awareness about diabetes-related complications, lack of access to medical care resulting from income disparities, lack of social supports, and heterogeneous quality of care are other societal factors that influence the diabetes-related cost of care [46]. Thus, this study finding will be useful for policy makers in planning future health care needs and allocating scarce resources. Furthermore, it will play a significant role for both patients and provider in identifying and quantifying the costs attributed to T2DM in Bangladesh.

A strength of this study was that it addressed all possible cost components of both direct (including hospitalisation) and indirect cost from the patients' perspective, and cost was calculated based on primary data. However, other recent COI studies have not addressed all cost components $[3,38]$, despite the cost being calculated from the societal perspective. Another strength was that a professional mix of patients residing in urban and rural locations was recruited randomly form six hospitals that provide primary to tertiary care.

Some limitations should also be noted. Firstly, in addition to direct and indirect costs, there are also intangible costs (e.g. pain, suffering, and loss of quality of life), which was not addressed in this study. Secondly, due to a lack of information, the calculation of indirect cost was done using the traditional human capital approach rather than the frictional cost approach [47]. Finally, as it was a descriptive cost-of-illness study, it did not provide information on the efficiency of resource use; thus, higher cost does not necessarily mean better services or value for money.

\section{Conclusions}

Diabetes is a major public health issue with a high economic burden in Bangladesh. The development and improvement of interventions toward better control of T2DM and the prevention of its complications are vital requirements for the country. Without these, in the near future, the private and public financing of diabetes treatment will be severely constrained, representing a health threat for the Bangladeshi population.

\section{Additional file}

Additional file 1: English language versions of the questionnaire (PDF $8 \mathrm{~kb}$ )

Abbreviations

BADAS: Diabetic Association of Bangladesh; BDT: Bangladeshi currency, Taka; BUHS: Bangladesh University of Health Sciences; Cl: Confidence interval;

COI: Cost -of-illness; GDP: Gross domestic product; IDF: International Diabetes Federation; LMICs: Low- and lower middle-income countries; OHA: Oral

hypoglycaemic agent; OOP: Out-of-pocket; PPS: Probability proportional to 
size; REDCap: Research Electronic Data Capture; T2DM: Type 2 diabetes mellitus; WHO: World Health Organization

\section{Acknowledgements}

We acknowledge the Bangladesh Diabetic Association for giving permission to collect data from its affiliated hospitals and all the study participants.

\section{Authors' contributions}

Concept and design (AA, BB), acquisition of data (AA, LA, SHH, AK), interpretation of data and drafting the manuscript (AA, KA, MJA, DJM, BB), critically review to improve the content and final approval of version to be submitted has done by all authors.

\section{Funding}

This research did not receive any specific grant from funding agencies in the public, commercial, or not-for-profit sectors.

\section{Availability of data and materials}

The data generated during and/or analysed during the current trial are available from the corresponding author on reasonable request.

\section{Ethics approval and consent to participate}

The study has been approved by the Monash University Human Research Ethics Committee (ID: 1469), the Ethical Review Committee of the Bangladesh University of Health Sciences and the Ethical Review Committee of the Diabetic Association of Bangladesh. Informed written consent was obtained from all participants.

\section{Consent for publication}

Not applicable.

\section{Competing interests}

The authors declare that they have no competing interests.

\section{Author details}

${ }^{1}$ Department of Epidemiology and Preventive Medicine, School of Public Health and Preventive Medicine, Monash University, 553 St. Kilda Rd., Level 4, Melbourne, VIC 3004, Australia. ${ }^{2}$ School of Population and Global Health, The University of Western Australia, Perth, Australia. ${ }^{3}$ Bangladesh University of Health Sciences (BUHS), Dhaka, Bangladesh. ${ }^{4}$ Bangladesh Institute of Research and Rehabilitation in Diabetes Endocrine and Metabolic Disorders (BIRDEM), Dhaka, Bangladesh. ${ }^{5}$ BakerIDI Heart and Diabetes Institute, Melbourne, Australia.

Received: 2 April 2019 Accepted: 19 August 2019

Published online: 27 August 2019

\section{References}

1. Rathmann W, Giani G. Global prevalence of diabetes: estimates for the year 2000 and projections for 2030. Diabetes Care. 2004;27(10):2568-9.

2. Cho NH, Kirigia J, Mbanya JC, Ogurstova K, Guariguata L, Rathmann W, et al. IDF DIABETES ATLAS. 8th ed; 2017.

3. Barcelo A, Aedo C, Rajpathak S, Robles S. The cost of diabetes in Latin America and the Caribbean. Bull World Health Organ. 2003;81(1):19-27.

4. Cho NH, Whiting D, Forouhi N, Guariguata L, Hambleton I, Li R, et al. IDF DIABETES ATLAS. 7th ed. Hallado en: http://www idf org/diabetesatlas/5e/ es/prologo: International diabetes federation; 2015.

5. Hussain A, Vaaler S, Sayeed M, Mahtab H, Ali SK, Khan AA. Type 2 diabetes and impaired fasting blood glucose in rural Bangladesh: a population-based study. Eur J Public Health. 2006;17(3):291-6.

6. Niti S, Amrit V, Gupta B, Jasdeep S. Prevalence and risk factors of diabetes mellitus among adults residing in field practice area of a teaching Hospital in Punjab. Health line J. 2015;6(1):57-62.

7. Akter S, Rahman MM, Abe SK, Sultana P. Prevalence of diabetes and prediabetes and their risk factors among Bangladeshi adults: a nationwide survey. Bull World Health Organ. 2014;92:204-13A.

8. World Health Organization. Bangladesh health system review. Manila: WHO Regional Office for the Western Pacific; 2015

9. Chuang L-M, Soegondo S, Soewondo P, Young-Seol K, Mohamed M, Dalisay $E$, et al. Comparisons of the outcomes on control, type of management and complications status in early onset and late onset type 2 diabetes in Asia. Diabetes Res Clin Pract. 2006;71(2):146-55.

10. Bangladesh Bureau of Statistics SalD, Ministry of Planning. national accounts statistic, 2018

11. Asian Development Bank, Poverty in Bangladesh. 2017.

12. Association AD. Economic costs of diabetes in the US in 2012. Diabetes Care. 2013;36(4):1033.

13. Hogan P, Dall T, Nikolov P. Economic costs of diabetes in the US in 2002. Diabetes Care. 2003;26(3):917

14. Bhattacharyya SK, Else BA. Medical costs of managed care in patients with type 2 diabetes mellitus. Clin Ther. 1999;21(12):2131-42.

15. Brown JB, Pedula KL, Bakst AW. The progressive cost of complications in type 2 diabetes mellitus. Arch Intern Med. 1999;159(16):1873-80.

16. Massi-Benedetti M. The cost of diabetes in Europe-type II: the CODE-2 study. Diabetologia. 2002;45(7):S1-4.

17. Lin T, Chou P, Tsai S-T, Lee Y-C, Tai T-Y. Predicting factors associated with costs of diabetic patients in Taiwan. Diabetes Res Clin Pract. 2004;63(2):119-25.

18. Ng CS, Toh MPHS, Ko Y, Lee JY-C. Direct medical cost of type 2 diabetes in Singapore. PLoS One. 2015;10(3):e0122795.

19. Afroz A, Habib SH, Chowdhury HA, Paul D, Shahjahan M, Hafez MA, et al. Healthcare cost of type 2 diabetes mellitus in Bangladesh: a hospital-based study. Int J Diabetes Dev Countries. 2016;36(2):235-41.

20. Kobelt G. Health economics: an introduction to economic evaluation. London: Office of health economics; 2002.

21. Harris PA, Taylor R, Thielke R, Payne J, Gonzalez N, Conde JG. Research electronic data capture (REDCap) — a metadata-driven methodology and workflow process for providing translational research informatics support. J Biomed Inform. 2009;42(2):377-81.

22. Rice DP. Estimating the cost of illness. Am J Public Health Nations Health. 1967:57(3):424-40.

23. Drummond MF, McGuire A. Economic evaluation in health care: merging theory with practice. Oxford: OUP; 2001.

24. Organization WH. WHO collaborating Centre for Drug Statistics Methodology: ATC classification index with DDDs and guidelines for ATC classification and DDD assignment. Oslo: Norwegian Institute of Public Health; 2006.

25. Moore R, Mao Y, Zhang J, Clarke K. Economic burden of illness in Canada, 1993. Chronic Dis Can. 1997;18(2):1F.

26. List of minimum wages by country, https://en.wikipedia.org/wiki/List_of_ minimum wages by country, Accessed 13 Jan 2018.

27. Billah B, Huq MM, Smith JA, Sufi F, Tran L, Shardey GC, et al. AusSCORE II in predicting 30-day mortality after isolated coronary artery bypass grafting in Australia and New Zealand. J Thorac Cardiovasc Surg. 2014; 148(5):1850-5 e2

28. Tharkar S, Devarajan A, Kumpatla S, Viswanathan V. The socioeconomics of diabetes from a developing country: a population based cost of illness study. Diabetes Res Clin Pract. 2010;89(3):334-40.

29. Khowaja LA, Khuwaja AK, Cosgrove P. Cost of diabetes care in out-patient clinics of Karachi, Pakistan. BMC Health Serv Res. 2007:7(1):189.

30. Wang W, McGreevey WP, Fu C, Zhan S, Luan R, Chen W, et al. Type 2 diabetes mellitus in China: a preventable economic burden. Am J Manag Care. 2009;15(9):593-601.

31. Krop JS, Powe NR, Weller WE, Shaffer TJ, Saudek CD, Anderson GF. Patterns of expenditures and use of services among older adults with diabetes: implications for the transition to capitated managed care. Diabetes Care. 1998;21(5):747-52.

32. Chaikledkaew U, Pongchareonsuk P, Chaiyakunapruk N, Ongphiphadhanakul $B$. Factors affecting health-care costs and hospitalizations among diabetic patients in Thai public hospitals. Value Health. 2008;11(s1):S69-74.

33. Vanderlee L, Ahmed S, Ferdous F, Farzana FD, Ahmed T, Hammond D, et al. Self-care practices and barriers to compliance among patients with diabetes in a community in rural Bangladesh. Int J Diabetes Dev Countries. 2016; 36(3):320-6

34. Köster I, Huppertz E, Hauner H, Schubert I. Direct costs of diabetes mellitus in Germany-CoDiM 2000-2007. Exp Clin Endocrinol Diabetes. 2011;119(06): 377-85.

35. Association AD. Economic costs of diabetes in the US in 2012. Diabetes Care. 2013;36:1033-46 Diabetes care. 2013;36(6):1797.

36. Esteghamati A, Khalilzadeh $\mathrm{O}$, Anvari M, Meysamie A, Abbasi M, Forouzanfar $M$, et al. The economic costs of diabetes: a population-based study in Tehran, Iran. Diabetologia. 2009;52(8):1520-7. 
37. Bahia LR, Araujo DV, Schaan BD, Dib SA, Negrato CA, Leão MP, et al. The costs of type 2 diabetes mellitus outpatient care in the Brazilian public health system. Value Health. 2011;14(5):S137-S40.

38. Association AD. Economic costs of diabetes in the US in 2007. Diabetes Care. 2008;31(3):596-615.

39. Jönsson B. Revealing the cost of type II diabetes in Europe. Diabetologia. 2002;45(7):S5-S12.

40. Björk S. The cost of diabetes and diabetes care. Diabetes Res Clin Pract. 2001;54:13-8.

41. Rosenzweig JL, Weinger K, Poirier-Solomon L, Rushton M. Use of a disease severity index for evaluation of healthcare costs and management of comorbidities of patients with diabetes mellitus. Am J Manag Care. 2002; 8(11):950-8.

42. Riewpaiboon A, Pornlertwadee P, Pongsawat K. Diabetes cost model of a hospital in Thailand. Value Health. 2007:10(4):223-30.

43. Ramachandran A, Ramachandran S, Snehalatha C, Augustine C, Murugesan $\mathrm{N}$, Viswanathan $\mathrm{V}$, et al. Increasing expenditure on health care incurred by diabetic subjects in a developing country. Diabetes Care. 2007;30(2):252-6.

44. Khowaja LA, Khuwaja AK, Cosgrove P. Cost of diabetes care in out-patient clinics of Karachi, Pakistan. BMC Health Serv Res. 2007;7(1):1.

45. Oglesby AK, Secnik K, Barron J, Al-Zakwani I, Lage MJ. The association between diabetes related medical costs and glycemic control: a retrospective analysis. Cost Eff Resour Alloc. 2006;4(1):1.

46. Kapur A. Economic analysis of diabetes care. Indian J Med Res. 2007;125(3):473.

47. Drummond MF, Sculpher MJ, Claxton K, Stoddart GL, Torrance GW. Methods for the economic evaluation of health care programmes. 4th ed. Oxford: Oxford university press; 2015.

\section{Publisher's Note}

Springer Nature remains neutral with regard to jurisdictional claims in published maps and institutional affiliations.

Ready to submit your research? Choose BMC and benefit from:

- fast, convenient online submission

- thorough peer review by experienced researchers in your field

- rapid publication on acceptance

- support for research data, including large and complex data types

- gold Open Access which fosters wider collaboration and increased citations

- maximum visibility for your research: over $100 \mathrm{M}$ website views per year

At BMC, research is always in progress.

Learn more biomedcentral.com/submissions 